\title{
TEOR DE ÁGUA LIMITE PARA CRIOCONSERVAÇÃO DE SEMENTES DE ROMÃ (Punica granatum L.)
}

Doi:http://dx.doi.org/10.1590/1809-4430-Eng.Agric.v35n2p313-321/2015

\section{LUZIA M. DE M. SILVA ${ }^{1}$, MARIO E. R. M. C. MATA ${ }^{2}$, MARIA E. M. DUARTE ${ }^{3}$}

RESUMO: Tradicionalmente, a determinação das condições ideais para a conservação de sementes é obtida através de experimentos que estudam a combinação dos fatores : teor de água e temperatura de armazenamento, monitorando a viabilidade das sementes ao longo do tempo. Ante o exposto, objetivou-se determinar o Teor de Água Limite para Crioconservação das sementes de romã, quando armazenadas nas temperaturas de -170 e $-196{ }^{\circ} \mathrm{C}$. As sementes passaram por um processo de umedecimento e secagem até atingirem os teores de água de $4 ; 6 ; 8 ; 10 ; 12$ e 14\% b.u.; logo após, foram crioconservadas durante cinco dias e, em seguida, descongeladas gradativamente nas temperaturas de $-196,-170,-80,10^{\circ} \mathrm{C}$ e ambiente, com intervalo de 3 horas para cada temperatura, para então serem realizados os testes de germinação e vigor. Para efeito de análise comparativa, utilizou-se da armazenagem das sementes a $25^{\circ} \mathrm{C}$ e $70 \%$ de umidade relativa por igual período de tempo (5 dias). $\mathrm{O}$ delineamento estatístico empregado foi o inteiramente casualizado, com arranjo fatorial $6 \times 3$, representado pelos teores de água e temperaturas, empregando-se quatro repetições por tratamento. Pode-se concluir que o melhor porcentual de germinação e vigor das sementes de romã foi obtido quando essas sementes foram crioconservadas em vapor de nitrogênio $\left(-170{ }^{\circ} \mathrm{C}\right)$, com um teor de água de $10 \%$ b.u.

PALAVRAS-CHAVE: sementes, armazenamento criogênico, qualidade fisiológica.

\section{WATER CONTENT LIMIT FOR CR YOPR ESERVATION OF POMEGRANATE SEEDS (Punica granatum L.)}

ABSTRACT: Traditionally, determining the ideal conditions for seed storage is obtained from experiments that study the combination of two factors: water content and storage temperature, monitoring the viability of the seeds over time. Based on the foregoing, the aim was to determine the water content limit to the freezing of the pomegranate seeds by cryogenics system, when stored at temperatures of -170 and $-196{ }^{\circ} \mathrm{C}$. The seeds have undergone to a process of wetting and drying until they achieve the moisture content of $4,6,8,10,12$, and $14 \%$ on wet basis; shortly after, they were cryopreserved for five days and then defrosted gradually at temperatures of -196, $-170,-80,10$ ${ }^{\circ} \mathrm{C}$ and room temperature with an interval of 3 hours for each temperature, in order to be conducted tests of germination and vigor. For purpose of a comparative analysis it was used storage of seeds at $25{ }^{\circ} \mathrm{C}$ and $70 \%$ relative humidity for the same period of time (5 days). The statistical design was completely randomized with $6 \times 3$ factorial arrangement represented by the water content and temperature, using four replicates per treatment. It can be concluded that the best percentage of germination and vigor of a pomegranate was obtained when these seeds were cryopreserved in nitrogen vapor $\left(-170{ }^{\circ} \mathrm{C}\right)$, with a water content of $10 \%$ w.b.

KEYWORDS: seeds, cryogenic storage, physiological quality.

\section{INTRODUÇÃO}

O Brasil possui uma das maiores diversidades vegetais do mundo e inúmeras experiências vinculadas ao conhecimento de plantas medicinais e tecnologia para correlacionar o saber popular e

\footnotetext{
${ }^{1}$ Tecnóloga de Alimentos, Doutoranda, Departamento de Engenharia Agrícola, UFCG/Campina Grande - PB, Fone: (83) 2101 1285, dluziamarcia@y ahoo.com

${ }^{2}$ Eng $^{\circ}$ A grônomo, Prof. Doutor, Departamento de Engenharia de Alimentos, UFCG/Campina Grande - PB, mario.cavalcanti@ufcg.edu.br

${ }^{3}$ Enga Agrícola, Prof $^{a}$ Doutora, Departamento de Engenharia de Alimentos, UFCG/Campina Grande - PB, elita.duarte@ufcg.edu.br Recebido pelo Conselho Editorial em: 02-10-2012 
o científico (ALBUQUERQUE \& HANAZAKI, 2006). No entanto, a extinção ainda é uma preocupação dos conservacionistas, pois representa o desaparecimento de linhagens evolutivas. A atividade humana, atra vés da redução e fragmentação de habitats, da introdução de novas espécies e da superexploração dos recursos naturais, é a principal responsável pela atual taxa de extinção das espécies e consequente perda de biodiversidade (PRIMACK \& RODRIGUES, 2006).

A conservação, em seu conceito mais amplo, representa a preservação, manejo e uso de recursos genéticos conhecidos, de forma que eles possam produzir o máximo de benefícios sustentáveis para a geração presente, enquanto mantém seu potencial para usos futuros (BIOVERSITY INTERNATIONAL, 2006). Nesse enfoque, vale salientar a importância do tema em estudo devido à importância da preservação dos recursos genéticos da espécie de romã (Punica granatum L.) na busca do seu melhoramento genético e na manutenção de estoques das sementes.

A espécie $P$. granatum é um arbusto ou pequena árvore nativa da Ásia e tem sido usada como adstringente, hemostática, antidiabética, anti-helmíntica e antidiarreica. É popularmente conhecida no Brasil como "romã" e seus frutos (pericarpo) são ricos em taninos hidrolisáveis, como a punicalagina, punicalina e ácido elágico. Também contém antocianosídeos, como 3-glucosídeos e 3-5, digluconosídeos de delfinidina, cianidina e pelargonidina. Além disso, contém ácidos orgânicos, incluindo ácido ascórbico e cítrico (CATÃO et al., 2006).

Consideradas uma das estruturas encarregadas da propagação das plantas, as sementes são constituídas de água e matéria seca, nas quais se encontram os polissacarídeos, proteínas, óleos, cinzas e vitaminas. O termo teor de água refere-se à quantidade de água existente na semente em relação à sua massa total, sendo esta, função da umidade relativa do ar e da temperatura do ambiente (ALMEIDA et al., 2006).

Determinar como o teor de água influencia a longevidade das sementes é logisticamente difícil porque os experimentos relacionados à deterioração de sementes são de longo prazo, exigindo muitos anos para detectar mudanças na viabilidade e no vigor das sementes. O princípio destes experimentos é simular, sob condições adversas (submeter lotes de sementes com diferentes teores de água a temperaturas elevadas), os mesmos processos de deterioração que as sementes teriam sob armazenamento em condições amenas (W ALTERS et al., 2005).

Para a obtenção de resultados confiáveis dos testes de germinação, é necessária a utilização de condições-padrão, indicadas nas Regras para Análises de Sementes (BRASIL, 2009). Isso significa que as condições sob as quais são realizados esses testes são controladas de forma a atender aos requisitos ambientais ideais à germinação das sementes de cada espécie.

A crioconservação tem-se revelado uma importante técnica para a manutenção da qualidade fisiológica de sementes e materiais vegetais armazenados. Essa técnica consiste na conservação do material em nitrogênio líquido à temperatura de $-196^{\circ} \mathrm{C}$ e na sua forma de vapor de nitrogênio à $170{ }^{\circ} \mathrm{C}$. Nessas temperaturas, os processos metabólicos que necessitam de energia térmica praticamente são paralisados, fazendo com que os processos de deterioração do material ocorram de forma muito lenta, podendo ser armazenados por períodos prolongados (COELHO, 2006).

Quando as condições ambientais são inadequadas e o teor de água de equilíbrio das sementes se eleva a determinados níveis que passam a ser impróprios para a conservação de um determinado material, inicia-se, nessas condições, a perda acentuada da qualidade fisiológica (GOLDFARB et al., 2008). Portanto, antes de crioconservar sementes, é necessário conhecer o teor de água ideal que as mesmas devem ser armazenadas na temperatura criogênica, pois se este teor de água ideal não for determinado, as sementes podem perder sua viabilidade durante o armazenamento criogênico, inviabilizando o uso dessa técnica.

Assim, o objetivo deste trabalho foi determinar o Teor de Água Limite para a Crioconservação (TALC) das sementes de romã (Punica granatum L.), levando-se em consideração a importância dos estudos referentes à exploração de forma racional dos recursos genéticos. 


\section{MATERIAL E MÉTODOS}

Os experimentos foram conduzidos no Laboratório de Sementes e no Setor de Criogenia do Laboratório de Armazenamento e Processamento de Produtos Agrícolas (LAPPA) da Unidade Acadêmica de Engenharia Agrícola, Universidade Federal de Campina Grande (UFCG - PB). Foram utilizadas sementes de romã oriundas de frutos fisiologicamente maduros (pericarpo amarelado com manchas vermelhas), adquiridos na Fazenda Águas do Tamanduá, no sertão paraibano de Sousa - PB, coletados no período de janeiro de 2012 (Figura 1). Os frutos foram lavados, sanitizados com água clorada (10 ppm de cloro livre) e cortados no sentido longitudinal para a remoção das sementes que, em seguida, foram colocadas sobre uma peneira e maceradas com um pistilo à temperatura ambiente $\left( \pm 25^{\circ} \mathrm{C}\right)$, imersas em água destilada por 24 horas para a remoção da sarcotesta, seguido de secagem à sombra.
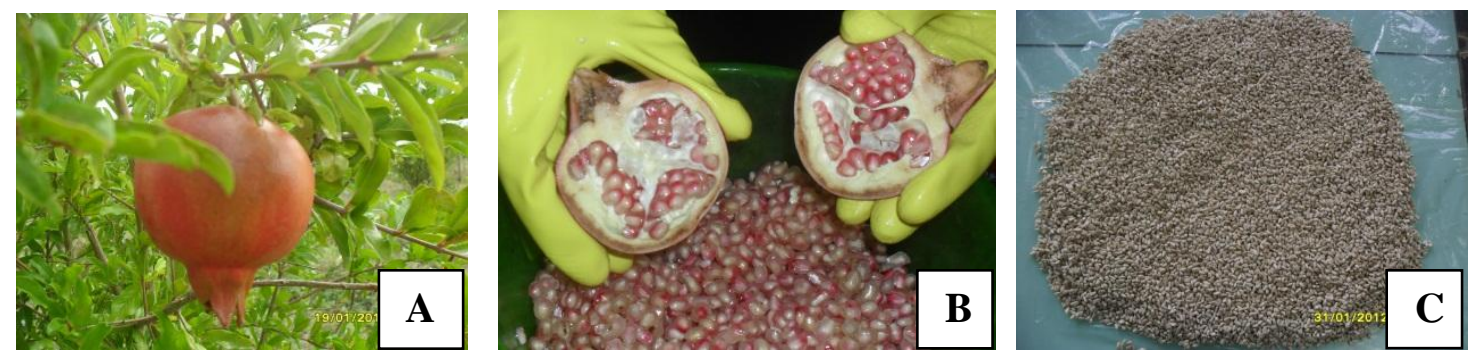

FIGURA 1. Fruto (A); Processamento (B); Sementes (C). Fruit (A); Processing (B); Seed (C).

A determinação do teor de água inicial das sementes (Equação 1) foi realizada a partir do método-padrão da estufa a $105 \pm 3{ }^{\circ} \mathrm{C}$, utilizando-se de quatro subamostras de $5 \mathrm{~g}$ de sementes, acond icionadas em recipientes metálicos, onde permaneceram durante 24 horas. Após esse período, foram retirados da estufa, tampados rapidamente, resfriados em dessecador durante 15 minutos e pesados em balança analítica com precisão de 0,0001, como prescrito nas Regras para Análise de Sementes (BRASIL, 2009). O resultado final foi expresso pela média aritmética das subamostras.

$$
\% \text { de Teor de Água }=\frac{100(P-p)}{P-t}
$$

em que,

$P=$ peso inicial, peso do recipiente e sua tampa mais o peso da semente úmida;

$p=$ peso final, peso do recipiente e sua tampa mais o peso da semente seca,

$t=$ tara, peso do recipiente com sua tampa.

Após a determinação do teor de água inicial, as sementes de romã foram submetidas a um processo de umedecimento ou secagem, até atingirem teores de água estabelecidos para os diferentes ensaios de determinação do TALC $(4 ; 6 ; 8 ; 10 ; 12$ e $14 \%$ b.u.).

No procedimento de secagem das sementes, as amostras foram colocadas em um dessecador contendo sílica gel, sendo realizadas pesagens consecutivas dos lotes até atingirem os pesos referentes aos teores de água desejados. Para o acréscimo do teor de água, as sementes foram umedecidas de forma uniforme, em cesta de arame com quatro suportes em sua base; este material foi colocado no interior de uma bandeja plástica com água destilada até o nível dos suportes, sem atingir as sementes. Todo o material (bandeja e cesta com sementes) foi envolvido por um saco plástico de alta densidade, vedado e, em seguida, levado a uma câmara de refrigeração com temperatura de $10{ }^{\circ} \mathrm{C}$, sendo pesado a cada hora, utilizando uma balança eletrônica, com precisão de $0,001 \mathrm{~g}$ até atingir os pesos referentes aos teores de água desejados. 
A perda ou ganho de água pelas sementes foi determinada por meio da [eq.(2)]:

$$
P_{f}=P_{i} \times \frac{100-X_{i}}{100-X_{f}}
$$

em que,

$P_{f}=$ peso final da amostra $(\mathrm{g}) ;$

$P_{i}=$ peso inicial da amostra $(\mathrm{g})$;

$X_{i}=$ teor de água inicial das sementes (\% b.u.),

$X_{f}=$ teor de água desejada das sementes (\% b.u $)$.

Os valores experimentais dos processos de umedecimento e secagem das sementes de romã foram ajustados a uma equação exponencial atra vés de regressão não-linear, em função do tempo em minutos. Esse comportamento foi avaliado tomando por base lotes de 1000 sementes, o que corresponde à massa de 29,32 g.

Para determinação do TALC, foram formados seis lotes de sementes com teores de água ajustados para $4 ; 6 ; 8 ; 10 ; 12$ e $14 \%$ em b.u. As sementes foram acondicionadas em tubos cilíndricos de alumínio (Canister), separadas por teor de água e acondicionadas em botijões criogênicos isolados com vácuo parcial (Figura 2), o que confere, ao botijão, a capacidade de manter o nitrogênio em estado líquido $\left(\mathrm{N}_{2} \mathrm{~L}\right)$ a $-196^{\circ} \mathrm{C}$ (CAVALCANTI MATA et al., 2004).

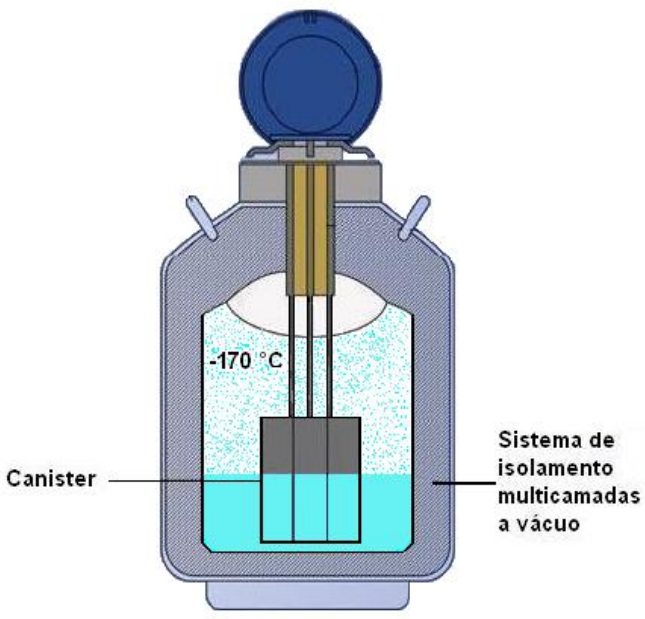

A

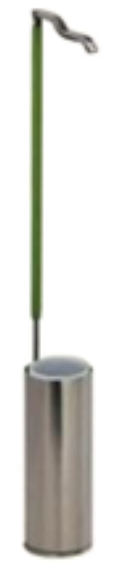

Canister

B

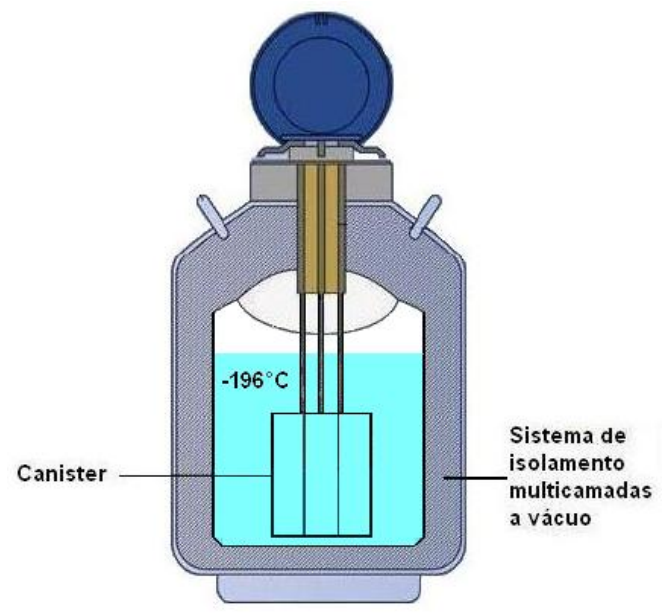

C

FIGURA 2. Botijão criogênico que armazena as sementes à temperatura de $-170{ }^{\circ} \mathrm{C}(\mathrm{A}) \mathrm{e}-196{ }^{\circ} \mathrm{C}$ (C). Cryogenic container that stores the seeds at a tempe rature of $-170{ }^{\circ} \mathrm{C}$ (A) and $-196^{\circ} \mathrm{C}(\mathrm{C})$.

Decorrido um período de cinco dias de crioarmazenamento, as sementes foram submetidas a descongelamento gradativo $\left(-196 ;-170 ;-80 ; 10{ }^{\circ} \mathrm{C}\right.$ e temperatura ambiente) com intervalo de três horas para cada temperatura. Em seguida, foram submetidas a uma avaliação da qualidade fisiológica através dos testes de germinação e de vigor. Para uma análise comparativa, os mesmos testes foram realizados para um lote de sementes armazenadas pelo período de cinco dias, à temperatura ambiente de aproximadamente $23{ }^{\circ} \mathrm{C}$ e umidade relativa (UR) média de $70 \%$.

Não há, nas Regras para Análise de Sementes (BRASIL, 2009), um protocolo que descreva a metodologia para avaliar as sementes de romã (Punica granatum L.); portanto, o teste de germinação adotado foi determinado através de procedimentos experimentais. Foram utilizadas quatro repetições de 50 sementes por tratamento, semeadas em bandejas plásticas com dimensão de $56 \times 31,5 \times 7,0 \mathrm{~cm}$. O substrato utilizado foi a vermiculita, que foi umedecida com água destilada, e, 
sempre que necessário, substrato era umedecido novamente; consideraram-se germinadas as sementes que emitiram $10 \mathrm{~mm}$ de radícula no $10^{\circ}$ dia após a semeadura, sendo as contagens realizadas a cada cinco dias.

Os testes de vigor foram determinados através do comprimento da plântula e do peso da matéria seca. Para a determinação do comprimento das plântulas, foi utilizado um paquímetro com precisão de $0,01 \mathrm{~mm}$, sendo a valiada a altura das plântulas normais (sistema radicular desenvolvido, presença de hipocótilo e cotilédones) (GOLDFARB et al., 2010). A determinação do peso da matéria seca, das plântulas consideradas normais de cada repetição, foi realizada retirando-as do substrato e colocando-as em saco de papel, as quais, separadas por tratamento e repetições, foram colocadas para desidratação em estufa a $70 \pm 3{ }^{\circ} \mathrm{C}$, até a obtenção do peso constante. Depois deste período, a matéria seca foi retirada da estufa e colocada para resfriar em um dessecador, pelo período de 15 minutos, seguido de pesagem em balança eletrônica, com precisão de $0,01 \mathrm{~g}$. O peso seco foi calculado através da fórmula proposta por VIERA \& CARVALHO (1994).

$\mathrm{O}$ delineamento estatístico empregado foi o inteiramente casualizado, com arranjo fatorial $6 \mathrm{X}$ 3 , representado pelos teores de água de $4 ; 6 ; 8 ; 10 ; 12$ e $14 \%$ em b.u. e temperaturas de $25,-170$ e $196^{\circ} \mathrm{C}$, empregando-se quatro repetições por tratamento. Foram realizadas a análise de variância e a comparação das médias dos tratamentos, pelo teste de Tukey, a 5\% de probabilidade, utilizando o programa computacional ASSISTAT, versão 7.6 beta (SILVA \& AZEVEDO, 2009).

\section{RESULTADOS E DISCUSSÃO}

O valor do teor de água inicial das sementes de romã foi de $10,6 \%$ (b.u.). Os valores experimentais referentes ao processo de umedecimento e secagem das sementes em função do tempo estão demostrados nas Figuras 3 e 4:

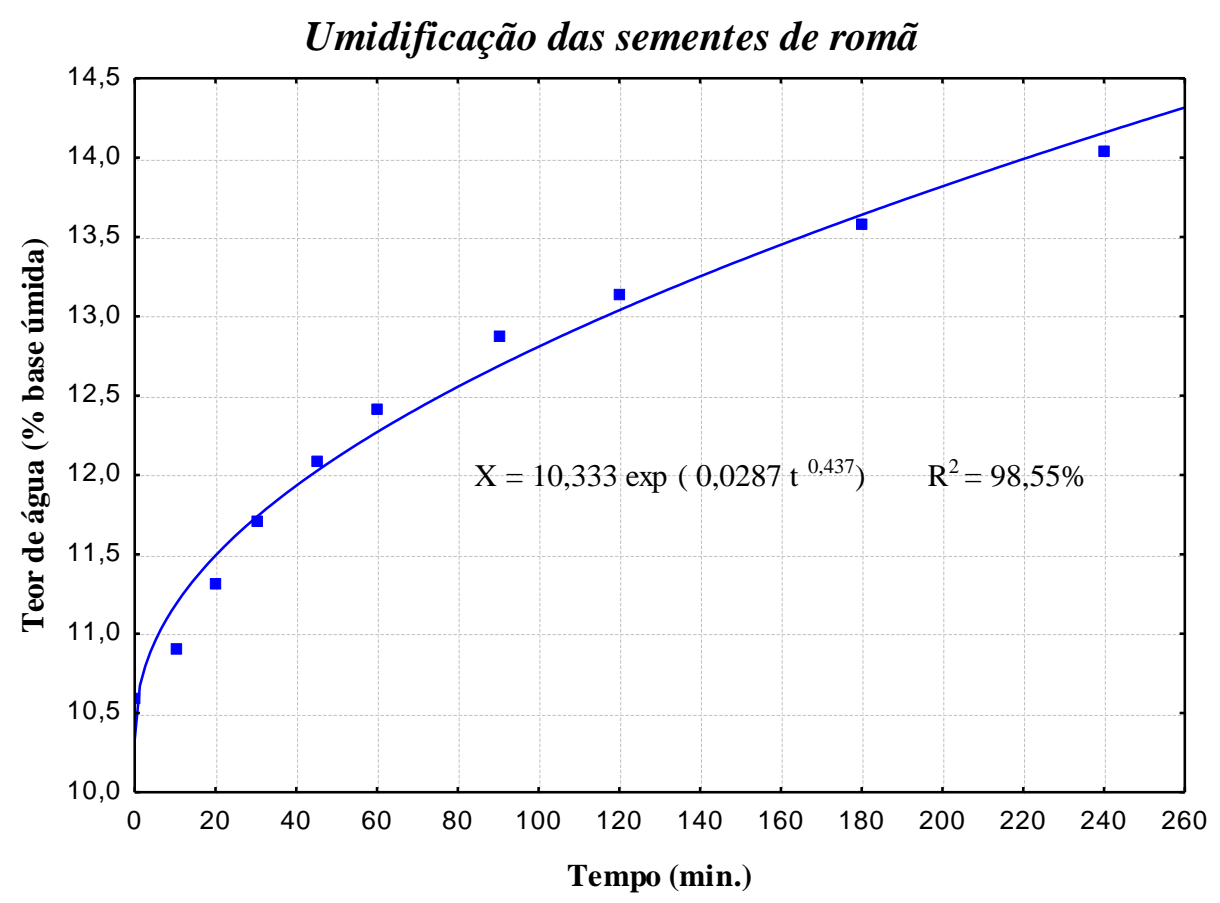

FIGURA 3. Valores experimentais do umedecimento das sementes de romã em função do tempo. Experime ntal values of the moistening of pomegranate seeds versus time. 
Secagem das sementes de romã

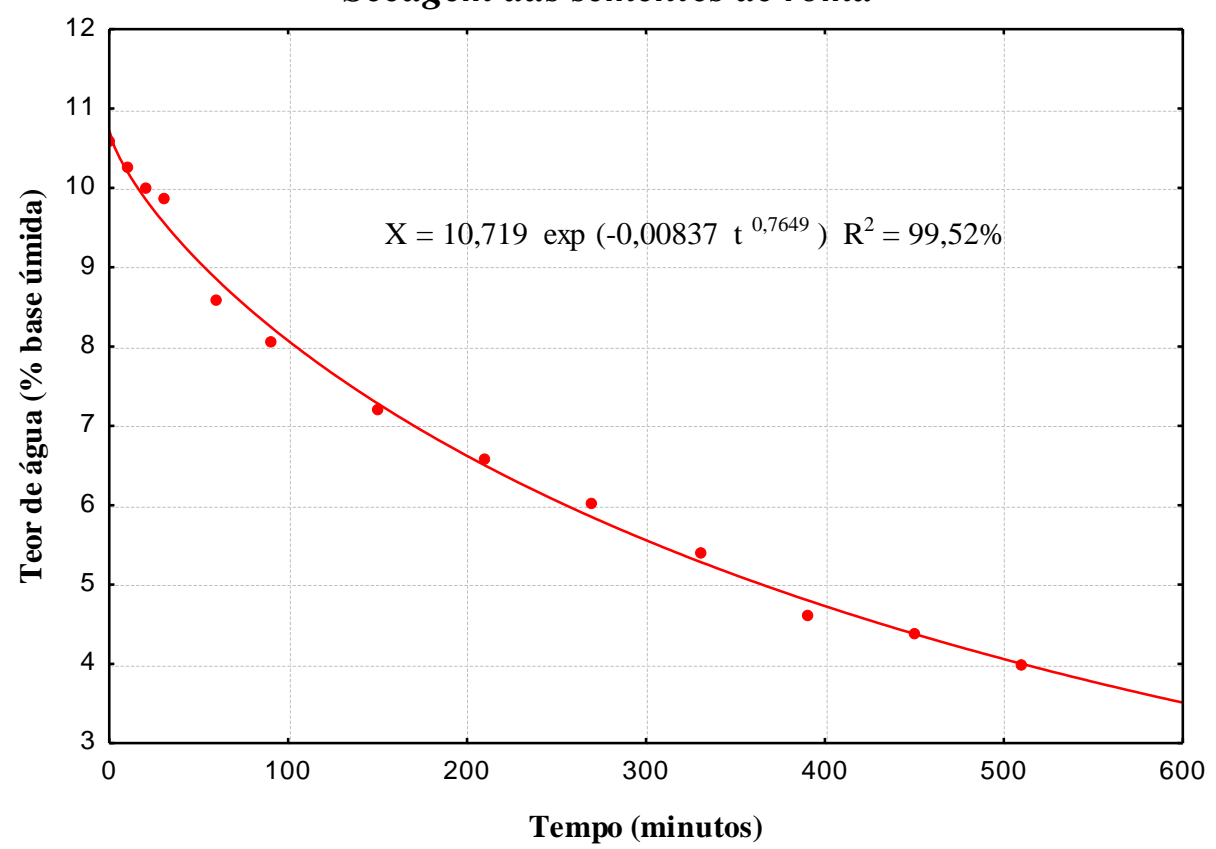

FIGURA 4. Valores experimentais da secagem das sementes de romã em função do tempo. Experime ntal values of pomegranate dried seeds versus time.

Os dados experimentais do processo de umedecimento e secagem foram ajustados por regressão. Tais processos foram facilitados pelo fato de as mesmas se encontrarem livres da sarcotesta, o que expõe o tegumento a maior absorção e desidratação. $O$ modelo não linear representou satisfatoriamente os valores experimentais, apresentando elevado valor para o coeficiente de determinação $\left(\mathrm{R}^{2}\right)$.

A germinação e o vigor das sementes de romã com os teores de água descritos anteriormente e submetidas à armazenagem por cinco dias, à temperatura ambiente $\left(25 \pm 2{ }^{\circ} \mathrm{C}\right)$, imersão em vapor de nitrogênio $\left(-170^{\circ} \mathrm{C}\right)$ e nitrogênio líquido $\left(-196^{\circ} \mathrm{C}\right)$, encontram-se na Tabela 1 . De acordo com os resultados, observou-se que as sementes com teor de água abaixo de $6 \%$ e acima de $12 \%$, quando imersas no vapor de nitrogênio e nitrogênio líquido, apresentaram redução dos valores de germinação, indicando resultados negativos quando expostas ao frio, além de apresentarem diferenças estatísticas entre os teores de água a 10 e 12\%, quando crioarmazenadas em nitrogênio líquido. Observou-se também que, para as sementes armazenadas à temperatura ambiente e crioarmazenadas em nitrogênio líquido, com teores de água entre 4 e $8 \%$ b.u., os resultados para germinação foram estatisticamente iguais para o teste de Tukey, a 5\% de probabilidade.

Diversas pesquisas têm demonstrado que o porcentual do teor de água das sementes interfere no processo de crioconservação. De acordo com TRESENA et al. (2010), sementes de ipê-amarelo com teores de água acima de $4 \%$ (b.u.) apresentaram um decréscimo significativo nos testes de germinação e vigor quando armazenadas à temperatura ambiente e crioarmazenadas em nitrogênio líquido. Já nos procedimentos experimentais realizados por GOLDFARB et al. (2008), as sementes de pinhão-manso podem ser crioconservadas à temperatura de $-196{ }^{\circ} \mathrm{C}$, com teor de água entre $4 \mathrm{e}$ $8 \%$ (b.u.), pois sua germinação e seu vigor não são alterados significativamente. No entanto, o teor de água limite para a crioconservação das sementes de pinhão-manso foi estabelecido como sendo $8 \%$ (b.u.).

Segundo MARCOS FILHO (2005), as variações de temperatura afetam a velocidade, a percentagem e a uniformidade de germinação. Portanto, a temperatura ótima é aquela que possibilita a combinação mais eficiente entre a porcentagem e a velocidade de germinação. 
TABELA 1. Valores médios de germinação e de vigor em função do teor de água das sementes de romã (Punica granatum L), armazenadas em crioconservação $\left(-170\right.$ e $\left.-196{ }^{\circ} \mathrm{C}\right)$ e à temperatura ambiente $\left(25{ }^{\circ} \mathrm{C}\right)$, por um período de cinco dias. Average values of germination and vigor according to water content of pomegranate seeds (Punica granatum L.), stored in cryopreservation $\left(-170\right.$ and $\left.-196{ }^{\circ} \mathrm{C}\right)$ and at room temperature $\left(25^{\circ} \mathrm{C}\right)$, for a pe riod of five days.

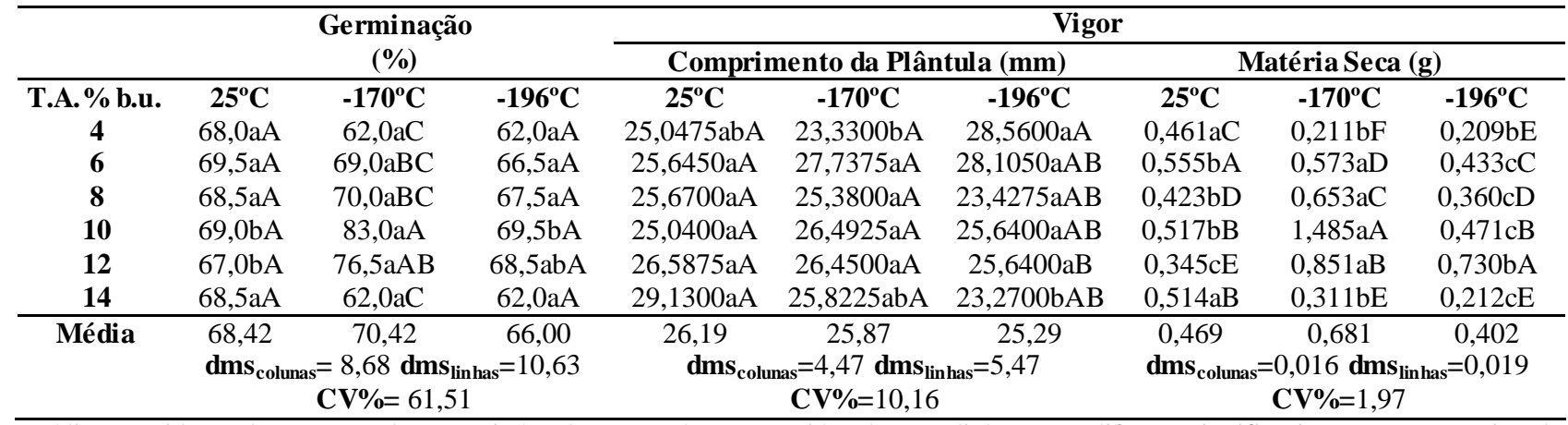

Médias seguidas pelas mesmas letras, minúsculas nas colunas e maiúsculas nas linhas, não diferem significativamente entre si, pelo teste de Tukey, a 5\% de probabilidade.

Ainda em relação à viabilidade dessa espécie, observa-se disparidade tanto na germinação como no vigor (matéria seca), na temperatura de $-170{ }^{\circ} \mathrm{C}$, indicando que a mesma é frágil com relação à sua armazenabilidade e qualidade fisiológica, sendo o teor de água limite para a crioconservação da semente, nessas condições, em torno de 10 a $12 \%$ b.u.

Em estudos referentes à manutenção de bancos de germoplasma, ALMEIDA (2006) afirma que o teor de água, a composição química e as velocidades de congelamento e descongelamento são fatores determinantes do efeito da crioconservação sobre as sementes, assim como as sementes de menor tamanho, uma composição química rica em lipídeos ou velocidade de congelamento/descongelamento inadequadas pode afetar a viabilidade das mesmas.

Nessa perspectiva, estabeleceu-se, ao longo dessas últimas décadas de pesquisa com crioconservação de sementes, que existiria um limite máximo de teor de água para o seu congelamento (High Moisture Freezing Limit - HMFL ou Teor de Água Limite para a Criopreservação - TALC), acima do qual a viabilidade das sementes fica reduzida (STANWOOD, 1985).

Buscando avaliar o sucesso da crioconservação, vários pesquisadores têm trabalhado nesse tema, como, por exemplo, ROCHA et al. (2009), que testaram as sementes das cultivares de algodoeiro BRS-Verde (V1), BRS-200-Marrom (V2), BRS-187-8H-Branco (V3) e 6M-Mocó-Branco (V4) provenientes da Empresa Brasileira de Pesquisa Agropecuária (CNPA/EMBRAPA). Neste trabalho, os autores concluíram que a crioconservação aumentou o percentual de germinação e de vigor das sementes de algodão, em razão de essa temperatura promover a quebra de dormência pela ação do frio.

Pesquisas a respeito da crioconservação de sementes de interesse econômico estão sendo cada vez mais estudadas, podendo citar GOLDFARB et al. $\left(2010^{\mathrm{a}}\right)$, que estudaram o armazenamento criogênico de sementes de pinhão-manso (Jatropha curcas L.), com o objetivo de preservação dos recursos genéticos dessa espécie para seleção, melhoramento genético e manutenção de estoques para o futuro. Esse trabalho mostrou que as sementes mantiveram sua viabilidade e os índices de vigor durante os períodos de crioconservação.

O comportamento apresentado pelas sementes de romã pode também estar associado à sensibilidade à des secação que algumas espécies apresentam, refletindo no processo de germinação. Segundo ROBERTS (1973) citado por LOPES et al. (2001), sementes que não toleram dessecação até níveis abaixo de 12 a $31 \%$ de teor de água, conforme a espécie, e que não sobrevivem em temperaturas subzero, recebem a denominação de recalcitrantes. Esta tolerância ou não à dessecação é de extrema importância, uma vez que desta depende a conservação das sementes a 
longo ou a curto prazo. Assim, há necessidade da realização de trabalhos que esclareçam se as sementes de romã permanecem ou não no grupo de recalcitrantes, bem como o comportamento dessas sementes frente a outras formas de extração da sarcotesta, com ênfase na eliminação de uma possível dormência causada pelo tegumento.

\section{CONCLUSÕES}

As sementes de romã (Punica granatun L.) com teores de água abaixo de 6\% e acima de $12 \%$ b.u., quando crioconservadas, têm sua germinação e vigor diminuídos significativamente.

O melhor percentual de germinação e vigor ( $1^{\text {a }}$ contagem e matéria seca) para as sementes de romã (Punica granatun L.) foi obtido quando essas sementes foram crioconservadas em vapor de nitrogênio $\left(-170^{\circ} \mathrm{C}\right)$, com teor de água de $10 \%$ b.u.

\section{REFERÊNCIAS}

ALBUQUERQUE U.P.; HANAZAKI N. As pesquisas etnodirigidas na descoberta de novos fármacos de interesse médico e farmacêutico: fragilidades e perspectivas. Revista Brasileira de Farmacognosia, São Paulo, v. 16, p.678-689, 2006. Suplemento.

ALMEIDA, F.A.C. Crioconservação de sementes na manutenção de banco de germoplasma. In: SIMPÓSIO BRASILEIRO DO URUCUM, 2006, João Pessoa. Anais... João Pessoa: EMEPA, 2006.

ALMEIDA, F.A.C.; DUARTE, M.E.M.; CAVALCANTI MATA, M.E.R.M. Teor de água na semente e sua relação com a tecnologia do armazenamento. In: ALMEIDA, F.A.C.; DUARTE, M.E.M.; CAVALCANTI MATA, M.E.R.M. (Ed). Tecnologia de armazenamento em sementes. Campina Grande: UFCG, 2006. p. 147-188.

BRASIL. Ministério da Agricultura, Pecuária e Abastecimento. Regras para análise de sementes. Brasília, DF: Secretaria de Defesa Agropecuária, 2009. 398 p.

BIOVERSITY INTERNATIONAL. Descriptors lists. Disponível em: <http://www.bio versityinternational.org/Themes/Germplasm_Documentation/Crop_Descripto/inde X.asp>. Acesso em: 13 fev. 2012.

CATÃO, R.M.R.; ANTUNES, R.M.P; ARRUDA, T.A.; PEREIRA, M.S.V; HIGINO, J.S.; ALVES, J.A.; PASSOS, M.G.V.M.; SANTOS, V.L. Atividade antimicrobiana "in vitro" do extratoetanólico de Punica granatum Linn. (romã) sobre isolados ambulatoriais de Staphylococcus aureus. Revista Brasileira de Análises Clínicas, Rio de Janeiro, v. 38, n. 2, p.111-114, 2006.

CAVALCANTI MATA, M.E.R.M. Tecnologia de crioconservação de sementes de urucum. Revista Tecnologia \& Ciência Agropecuária, João Pessoa, v.2, n.1, p.1-9, mar., 2008. Apresentado no Simpósio Brasileiro do Urucum, em João Pessoa, Paraíba, Brasil, Abril 2006.

CAVALCANTI MATA, M.E.R.M.; ROCHA, M. do S.; DUARTE, M.E.M. Teor de água limite para crioconservação de sementes de algodão arbóreo variedade 6M. Revista Brasileira de Produtos Agroindustriais, Campina Grande, v.6, n.2, p.179-189, 2004.

COELHO, R.R.P. Protocolo de crioconservação de sementes de algodão (Gossypium hirsutum L. raça Latifolium Hutch.) cultivares BRS 200 marrom e BRS verde. 2006. 89f. (Tese de Doutorado) Universidade Federal da Paraỉba, João Pessoa, 2006.

GOLDFARB, M.; DUARTE, M.E.M.; CAVALCANTI MATA, M.E.R.M. Armazenamento criogênico de sementes de pinhão manso (Jatrophacurcas L.) Euphorbiaceae. Revista Biotemas, Florianópolis, v.23, n.1, p.27-33, mar., 2010.

GOLDFARB, M.; DUARTE, M.E.M.; CAVALCANTI MATA, M.E.R. M; PIMENTEL, L.W.; SEVERINO, L.S. Cinética de congelamento criogênico de sementes de pinhão manso (Jatropha curcas L.). Revista Engenharia Ambiental, Espírito Santo do Pinhal, v.7, n.1, p.195-203, jan. /mar., 2010. 
GOLDFARB, M.; DUARTE, M.E.M.; CAVALCANTI MATA, M.E.R.M; PIMENTEL, L.W.; SEVERINO, L.S. Teor de Água Limite para Crioconservação das sementes de pinhão manso (Jatropha curcas L.). Revista Brasileira de Produtos Agroindustriais, Campina Grande, v.10, n.2, p.121-129, 2008.

LOPES, K.P.; BRUNO, R. DE L.A.; BRUNO, G.B.; AZEREDO, G.A. DE. Comportamento de sementes de romã (Punica granatum L.) submetidas à fermentação e secagem. Revista Brasileira de Fruticultura, Jaboticabal, v.23, n.2, p.369-372, 2001.

MARCOS FILHO, J. Fisiologia de sementes de plantas cultivadas. Piracicaba: FEALQ, 2005. 495 p.

PRIMACK, R.B.; RODRIGUES, E. Biologia da conservação. Londrina: Ed. Planta, 2006.

ROCHA, M.S.; CAVALCANTI MATA, M.E.R.M.; CARVALHO, J.M.F.C.; LOPES, K.P. Crioconservação de sementes de algodão. Revista Brasileira de Engenharia Agrícola e Ambiental, Campina Grande, v.13, n.3, p.312-318, 2009.

STANWOOD, P.C. Cryopreservation of seed germplasm for genetic conservation. In: KARTHA, K.K . (Ed.). Cryopreservation of plant cells and organs. Boca Rotan: CRC Press, p.199-225, 1985.

SILVA, F. DE A.S.; AZEVEDO, C.A.V. DE. Principal Components Analysis in the Software Assistat-Statistical Attendance. In: WORLD CONGRESS ON COMPUTERS IN AGRICULTURE, 7., 2009, Reno, NV - Proceedings... St Joseph: American Society of Agricultural and Biological Engineers, 2009.

TRESENA, N. L.; CAVALCANTI MATA, M.E.R.M; DUARTE, M.E.M.; MORAES, A.M. Determinação do teor de água limite para crioconservação das sementes de ipê amarelo (Tabebuia chrysotrica (Mart. Ex. DC.) Stand1.). Revista Cerne, Lavras, v.16, n.2, p.171-175, abr./jun, 2010. VIEIRA, R.D.; CARVALHO, N.M. Teste de vigor em sementes. São Paulo - SP: Editora Afiliada, 1994. $164 \mathrm{p}$.

WALTERS, C.; WEELER, L.M.; GROTENHUIS, J.M. Longe vity of seeds stored in a genebank: species characteristics. Seed Science Research, Wallingford, v.15, p.1-20, 2005. 